\title{
Dimensões psicológica e espiritual de pais de crianças vivendo com HIV e AIDS
}

RESUMO | Objetivo: investigar a qualidade de vida de pessoas vivendo com HIV e aids, segundo dimensões psicológica e espiritual. Método: Investigação exploratória, descritiva, com enfoque misto. Participaram do estudo 18 usuários de um Hospital Escola em João Pessoa - PB. Utilizou-se a técnica de gravação em aparelho mp3, as quais foram transcritas na íntegra, no programa de texto Notepad. Após essa etapa, para análise das respostas utilizou-se o software IRAMUTEQ. Resultados: 83,3\% eram do sexo feminino, 38,8\% encontravam-se entre 19 e 32 anos de idade e $55,5 \%$ eram casados. 50\% concluiu o segundo grau e $44,4 \%$ são católicos. Dos discursos, emergiram as categorias dimensão psicológica relacionada à necessidade de ajuda; dimensão espiritual relacionada à necessidade de ajuda e dimensão espiritual de cuidado e saúde do ser humano. Conclusão: As dimensões emocional e espiritual devem ser abordadas no cuidado às pessoas que vivem com HIV e aids.

Palavras-chaves: Síndrome de Imunodeficiência Adquirida; Qualidade de Vida; Espiritualidade.

ABSTRACT | Objective: to investigate the quality of life of people living with HIV and aids, according to psychological and spiritual dimensions. Method: Exploratory, descriptive research, with a mixed focus. Eighteen users of a teaching hospital in João Pessoa - PB participated in the study. The recording technique on an $\mathrm{mp3}$ device was used, which were fully transcribed in the Notepad text program. After this step, the IRAMUTEQ software was used to analyze the responses. Results: $83.3 \%$ were female, $38.8 \%$ were between 19 and 32 years of age and $55.5 \%$ were married. $50 \%$ completed high school and $44.4 \%$ are catholic. From the speeches, the categories psychological dimension related to the need for help emerged; spiritual dimension related to the need for help and spiritual dimension of care and health of the human being. Conclusion: The emotional and spiritual dimensions must be addressed in caring for people living with HIV and aids.

Keywords: Acquired Immunodeficiency Syndrome; Quality of Life; Spirituality.

RESUMEN I Objetivo: investigar la calidad de vida de las personas que viven con HIV y sida, de acuerdo con las dimensiones psicológicas y espirituales. Método: investigación exploratoria, descriptiva, con un enfoque mixto. Dieciocho usuarios de un hospital docente en João Pessoa - PB participaron en el estudio. Se utilizó la técnica de grabación de mp3, que se transcribió en su totalidad, en el programa de texto del Bloc de notas. Después de este paso, se utilizó el software IRAMUTEQ para analizar las respuestas. Resultados: $83.3 \%$ eran mujeres, $38.8 \%$ tenían entre 19 y 32 años y $55.5 \%$ estaban casados. $50 \%$ completaron la escuela secundaria y $44.4 \%$ son católicos. A partir de los discursos, surgieron las categorías psicológicas relacionadas con la necesidad de ayuda; dimensión espiritual relacionada con la necesidad de ayuda y dimensión espiritual del cuidado y la salud del ser humano. Conclusión: las dimensiones emocionales y espirituales deben abordarse en el cuidado de las personas que viven con el HIV y sida. Palabras claves: Síndrome de Inmunodeficiencia Adquirida; Calidad de Vida; Espiritualidad.

\section{Sergio Vital da Silva Junior}

Mestre em Enfermagem. Enfermeiro. Universidade Federal da Paraíba (UFPB). Membro do Núcleo de Estudos e Pesquisas em Agravos Infecciosos e Qualidade de Vida - UFPB.

\section{Wilton José de Carvalho Silva}

Enfermeiro. Mestrando em Saúde Pública em Região de Fronteira. Universidade Estadual do Oeste do Paraná.

\section{Elismar Pedroza Bezerra}

Mestre em Gerontologia. Enfermeira Hospital Universitário Lauro Wanderley (HULW-UFPB). João Pessoa, Paraíba, Brasil.

\section{Helga de Sousa Soares}

Enfermeira - Hospital Universitário Lauro Wanderley (HULW-UFPB). João Pessoa, Paraíba, Brasil.

\section{Ana Elizabeth Lopes de Carvalho}

Mestre em Enfermagem. Enfermeira. Universidade de Pernambuco e Prefeitura do Recife. Pernambuco, Brasil.

\section{Fabieny da Silva Soares}

Enfermeira. Especialista em Unidade de Terapia Intensiva, Urgência e Emergência e Obstetrícia. Coordenadora do Curso Técnico em Enfermagem do Centro de Ensino Técnico da Paraíba (CETEPA).

\section{Solange Monteiro Moreira}

Enfermeira. Especialista em Saúde da Família. Hospital Universitário Lauro Wanderley (HULW-UFPB). João Pessoa, Paraíba, Brasil.

Recebido em: 27/01/2020

Aprovado em: 19/02/2020

\section{Maria Eliane Moreira Freire}

Doutora em Enfermagem. Enfermeira. Docente no Departamento de Enfermagem Clínica e no Programa de Pós-graduação em Enfermagem na Universidade Federal da Paraíba. Vice-líder do Núcleo de Estudos e Pesquisas em Agravos Infecciosos e Qualidade de Vida da Universidade Federal da Paraíba, João Pessoa-PB/Brasil.

\section{INTRODUÇÃO}

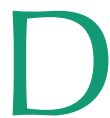
esde os primórdios da infecção pelo vírus da imunodeficiência humana (HIV), a Síndrome da Imunodeficiência Adquirida (aids) configura-se um problema de saúde pública mundial. Existe uma concentração dos casos no Sudeste e Sul, correspondendo a $54,4 \%$ e $20,0 \%$ do total de casos identificados de 1980 até junho de 2014; as regiões Nordeste, Centro-Oeste e Norte 
correspondem a $14,3 \%, 5,8 \%$ e $5,4 \%$ do total dos casos, respectivamente. O tempo de sobrevida do paciente vivendo com HIV e aids aumentou após a introdução da terapia antirretroviral de alta potência (HAART), a partir de 1996, sendo a distribuição proporcional dos casos de AIDS por regiões no cenário nacional ${ }^{(1)}$.

Na modernidade, o HIV é uma das principais condições infecciosas emergente, pela sua magnitude e extensão de danos causados às sociedades do mundo inteiro. Destaca-se a transmissão vertical que ocorre através da passagem do vírus da mãe para o bebê durante a gestação, trabalho de parto ou parto propriamente dito decorrente do contato com as secreções cérvico-vaginais e sangue materno ou a amamentação. Estima-se que cerca de 12 mil recém-nascidos sejam expostos ao HIV ao ano ${ }^{(2)}$.

A gestante que vive com essa condição de saúde também se confronta com a possibilidade de que a infecção se manifeste nela, ou em seu filho, caso se dê a transmissão vertical pela ineficácia das medidas profiláticas. Diante desta possibilidade, o conjunto de suas expectativas sobre a maternidade veicula-se a uma condição existencial, na qual a morte não é só imaginária, mas uma possibilidade real, podendo até ser apreendida como imediata ${ }^{(3)}$.

Nesse sentido, com o avanço tecnológico e cientifico do cuidado, os profissionais da área da saúde passam a desenvolver grande interesse no construto Qualidade de Vida (QV), que consoante com os novos paradigmas passaram a nortear as práticas destes profissionais que lidam com o cuidado de pessoas que vivem com HIV e aids.

A QV é uma entidade subjetiva, multidimensional, por receber influências (quantitativas e qualitativas) das dimensões física, psicológica, ambiental, social e espiritual, podendo diferir de indivíduo para indivíduo, e que até mesmo no próprio indivíduo pode variar ao longo do tempo ${ }^{(4)}$.

Um projeto multicêntrico envolvendo diferentes culturas destacou três aspectos de grande relevância para o constructo QV: a subjetividade, a multidimensionalidade e a bipolaridade(5). Destarte, o termo Qualidade de Vida Relacionada à Saúde (QVRS), que envolve de um modo geral a percepção da saúde e do impacto dos aspectos físicos, sociais, psicológicos e espirituais sobre ela, que incluem aqueles aspectos relacionados à saúde, mas excluem outros mais genéricos como, por exemplo, ganho salarial, liberdade e qualidade do meio ambiente ${ }^{(6,7)}$.

Ante o exposto, este estudo buscou respostas ao seguinte questionamento: que aspectos da qualidade de vida de pessoas vivendo com HIV e aids sofrem interferência segundo as dimensões psicológica e espiritual? Para responder à questão proposta, a presente pesquisa teve como objetivo: investigar a qualidade de vida de pessoas vivendo com HIV e aids, segundo dimensões psicológica e espiritual.

\section{MÉTODO}

A presente investigação é um estudo exploratório e descritivo, com enfoque misto. Na abordagem qualitativa, entende-se que há uma relação dinâmica entre a realidade e o sujeito, havendo assim um vínculo entre ambos, indissociável que é traduzido através da interpretação dos fenômenos e significados que emergem dos dados ${ }^{(8)}$.

A presente pesquisa foi desenvolvida no Serviço de Atendimento Especializado - SAE, de um hospital escola localizado no município de João Pessoa, PB. Este serviço oferece atendimento a muIheres gestantes, não gestantes, parceiros e crianças até os 13 anos de idade que vivem com HIV e aids.

A população do estudo foi composta por mulheres e homens cadastrados e atendidos no serviço citado, por serem soropositivos para o HIV e/ou seus filhos. Para composição da amostra foram adotados os seguintes critérios de inclusão: mãe e/ou pai vivendo com HIV e aids, em acompanhamento terapêutico no referido serviço; mãe e/ou pai de criança soropo- sitiva ou sorointerrogativa para HIV, ou vivendo com aids, em acompanhamento terapêutico nesse serviço. Assim, a amostra constituiu-se por acessibilidade, ou seja, os pesquisadores selecionaram os participantes a que tiveram acesso para o estudo e que atenderam aos critérios de inclusão estabelecidos, admitindo que estes pudessem representar o universo do estudo ${ }^{(9)}$.

Para viabilizar a coleta de dados foi adotada a técnica de entrevista, norteada por um roteiro semiestruturado, contemplando dados sociodemográficos (sexo, idade, escolaridade, estado civil, atividade laboral, renda mensal familiar, religião, atividade de lazer) e questões objetivas e subjetivas relativas ao objeto do estudo. As perguntas versavam sobre a dimensão emocional/psicológica e sobre a dimensão espiritual.

A etapa de coleta de dados ocorreu no período de março a abril de 2019 após apreciação e aprovação pelo comitê de ética em pesquisa, anuência da direção do serviço e dos participantes. Utilizou-se para o registro das respostas às questões subjetivas, o sistema de gravação em aparelho mp3.

A análise dos dados empíricos foi realizada mediante a análise estatística descritiva simples, apresentada com distribuição de frequência em números absolutos para variáveis sociodemográficas e clínicas; os dados subjetivos oriundos das entrevistas foram analisados por meio do software Interface de R pour lês Analyses Multidimensionnelles de Textes et de Questionnaires (IRAMUTEQ).

Compuseram a amostra 18 usuários do SAE. Para a técnica de entrevista, o pesquisador aproximou-se dos colaboradores que aguardavam atendimento ambulatorial, apresentando-se e solicitando a participação destes, esclarecendo-os acerca dos objetivos e do Termo de Consentimento Livre e Esclarecido. Após anuência, eram realizadas as perguntas por meio de gravação em mp3, e ouvidas as respostas.

Para o desenvolvimento da técnica o pesquisador do estudo conduziu a en- 
trevista orientando-se por um roteiro de perguntas semiestruturadas, elaborado no sentido de nortear a conversa e apreender o ponto de vista dos sujeitos entrevistados sobre a temática Objeto de estudo. Durante toda a entrevista, o pesquisador permitiu o livre discurso e ao mesmo tempo o delineamento da conversa, buscando manter a entrevista sintonizada com os objetivos da pesquisa. As falas das entrevistas foram gravadas em aparelho digital e para seu encerramento utilizou-se o critério de saturação, isto é, quando, após as informações coletadas com certo número de mulheres, novas entrevistas passaram a apresentar uma quantidade de repetições em seu conteúdo ${ }^{(10)}$.

Encerradas as entrevistas, as gravações foram transcritas na íntegra, no programa de texto Notepad, constituindo o Corpus de entrevistas. Após essa etapa, para o processamento dos dados, utilizou-se o software IRAMUTEQ. Trata-se de um programa livre que se ancora no software $R$, e que permite processamento e análises estatísticas de textos produzidos. Foi desenvolvido na língua francesa, mas atualmente possui tutoriais completos em outras línguas $^{(11)}$. O IRAMUTEQ possibilita os seguintes tipos de análises: pesquisa de especificidades de grupos, classificação hierárquica descendente, análise de similitude e nuvem de palavras ${ }^{(12)}$.

Em observância às normas éticas de pesquisas envolvendo seres humanos no cenário brasileiro, referenciados na Resolução CNS no 466/2012(13), o projeto de pesquisa foi submetido à apreciação do Comitê de Ética em Pesquisa, do Hospital Universitário Lauro Wanderley, CAAEE 56340516.4.0000.5183, tendo sido aprovado sob parecer: 1662882 .

\section{RESULTADOS}

Participaram do estudo 18 (100\%) usuários do Serviço de Atendimento Especializado de um Hospital Escola na cidade de João Pessoa. Destes, 15 (83,3\%) eram do sexo feminino. Com idade média entre 27 anos, variando entre 16 e 47 anos. A

maioria dos entrevistados, sete, (38,8\%) estavam entre 20 a 25 anos. Quanto ao estado civil, os respondentes afirmaram que $10(55,5 \%)$ eram casados, seis $(33,3 \%)$ solteiros e dois $(11,1 \%)$ divorciados.

Com relação a religião, oito $(44,4 \%)$ seguiam o catolicismo, sete $(38,8 \%)$ o protestantismo; um (5,6\%) afirmou ser espírita e dois $(11,2 \%)$ participantes alegaram não ter religião.

Quanto à escolaridade, nove participantes (50\%) afirmaram terem concluído o segundo grau; oito $(44,4 \%)$ concluíram o primeiro grau enquanto que um $(5,6 \%)$ participante alegou nunca ter estudado.

Referente ao tempo de diagnóstico do filho, três (16,6\%) apresentavam três anos de diagnóstico; dois $(11,2 \%)$ ainda estavam investigando a soropositividade do filho; e os demais participantes entre um mês a 11 anos de diagnóstico. É importante destacar que todas as mães entrevistadas afirmaram não amamentar seus filhos desde o nascimento.

Ao serem questionados acerca da sua profissão, as respostas dos participantes foram variadas, sendo apresentadas as seguintes respostas: quatro $(22,2 \%)$ vendedor, três (54\%) faxineiro, dois $(11,1 \%)$ comerciante, dois $(11,1 \%)$ professor de ensino médio,

Figura 1- Nuvem de palavras sobre qualidade de vida de pais de crianças vivendo com HIV e aids na perspectiva das dimensões psicológica e espiritual da saúde do ser humano. João Pessoa, 2020 ( $n=18)$.

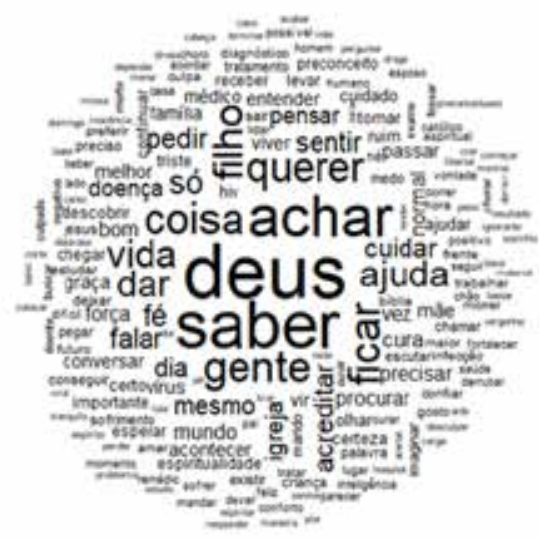

Revista Nursing, 2020; 23 (263): 3672-3677 
Quando questionados sobre os sentimentos ao solicitar ajuda, os entrevistados referiram algumas sensações que estão ligadas à sua dimensão psicológica. Segundo eles, ao necessitarem da ajuda de outrem, sentem que as atividades desempenhadas não são satisfatórias, como seria caso fossem desempenhadas por eles mesmos. Sentem ainda a possibilidade de morte iminente, o que faria deixarem de desempenhar atividades de vida diária, acarretando sofrimento aos seus dependentes. A culpabilidade também aparece nos discursos das pessoas que vivem com HIV e aids.

Eu quero eu mesma cuidar das minhas filhas, não quero contar com a ajuda de ninguém porque eles não vão cuidar como nós que somos mãe cuidamos. (P1)

Espero coisa boa. Que não aconteça coisa ruim tão cedo comigo para continuar cuidando das minhas filhas. (P2)

Sempre que ele precisar o que depender de mim faria o possível. (P2)

Eu acho que às vezes as pessoas não querem ajudar; fazem as coisas por pena. (P3)

Acho que às vezes minha família me culpa, mas eles sempre me ajudam muito. Acho que não tenho culpa, não iria querer isso para ele. (P4)

Gosto nem de pensar acho que é muito sofrimento me bate um nervosismo quando penso nisso. (P5)

As falas evidenciam os sentimentos na esfera psicológica dos indivíduos, os quais acreditam ser a ajuda, algo que menospreza quem é ajudado, o faz sentir menor em relação a quem ajuda. A cronicidade da aids advinda com o tratamento antirretoviral, pode interferir na saúde física, mental e no bem estar das pessoas que fazem uso dessa terapia, acarretando situações negativas nas atividades de vida diaria e por conseguinte na qualidade de vida desses indivíduos.
A família, diante da necessidade de cuidar de um de seus membros, percebe-se fragilizada diante desse processo de doença, e passa a buscar ajuda para suportar e superar tais dificuldades; neste enfrentamento, elas encontram o apoio que necessitam na religião ou espiritualidade, apegando-se a fé como uma esperança de cura e ou resiliência.

Em alguns momentos, os participantes da pesquisa fizeram distinção do que seria ajuda física, a qual, muitas das vezes é recebida como uma situação que menospreza e deprime fazendo com que a pessoa com HIV e aids se sinta vitimada; e a ajuda advinda de Deus, a qual é edificante e grandiosa, pois é considerada repleta de misericórdia e bondade.

É melhor você conversar com Deus porque ele pode te ajudar do que você conversar com uma pessoa que seja falsa com você e que não vai Ihe ajudar em nada. Ao contrário ela vai lhe atirar pedra. (P1)

Às vezes Deus usa as pessoas. Ele toca nas pessoas para ajudar alguém. Eu vejo assim quando recebo alguma ajuda isso não é dele, foi Deus que mandou. (P5)

A partir desses relatos, é importante que as pessoas envolvidas no apoio espiritual busquem novos horizontes de compreensão e acompanhamento às pessoas com o HIV e aids, não obstante, é desafiante e necessário pensar em algumas ferramentas que possam ser utilizadas na restituição das condições físicas, sociais, econômicas e espirituais para essa população.

Os relatos a seguir mostram o quanto a figura de Deus denota um alívio na luta diária das pessoas que vivem com HIV e aids:

Ás vezes eu vejo as pessoas correndo, trabalhando, perdendo tanto tempo em internet e tendo menos tempo com os filhos com a família, e a religião me faz ver isso, que com Deus tudo fica mais fácil, me aproxima mais de Deus, a pensar um pouco mais em nós, agradecer a Deus todos os dias porque a vida continua. (P1)

Deus nos dá força, Ele cura, liberta da ansiedade, do medo e da aflição [...] eu tenho muito e ainda hoje quando vêm certas coisinhas no pensamento. (P5)

Além de Deus nos dar a cura, temos que ter a convicção e a certeza que ele existe a gente tem que ter a fé e a certeza que ele vai nos curar [...] agora é óbvio que a gente tem que usar a fé [...] ele deu a inteligência ao homem para ele se especializar e estudar e a gente correr atrás de um médico. [...] porque Deus é o médico dos médicos, mas Deus deu a inteligência, então a gente tem que usar a fé com a inteligência: tem que ir no médico tem que se cuidar e tomar as medidas. (P11)

\section{DISCUSSÃO}

Em estudos relacionados à QV de pessoas vivendo com HIV e aids, predomina o sexo masculino, entretanto, o sexo feminino aparece com relativo aumento nas últimas décadas, apresentando baixos escores de qualidade de vida quando comparados a indivíduos sadios. (14). Atualmente a epidemiologia da Aids no Brasil caracteriza-se pela heterossexualização, feminização, faixa etária jovem e com baixo nível de escolaridade ${ }^{(15)}$.

Apesar de ainda haver mais casos de AIDS entre os homens do que entre as mulheres, essa diferença tem diminuído ao longo dos anos, indicando o avanço do processo de feminização, no qual o número de mulheres infectadas aumenta rapidamente entre as heterossexuais casadas, com parceiro único e não-usuárias de drogas, sendo a relação sexual a principal via de transmissão do HIV para essas mulheres ${ }^{(16)}$.

Estudos realizados com mulheres brasileiras casadas e portadoras do vírus revelaram que a maioria considerava a 
convivência prolongada com o parceiro como uma forma de segurança contra o HIV. Aliado a estes fatores, está a maior vulnerabilidade feminina a nível morfológico e biológico que se relaciona a maior área de exposição da mucosa vaginal aos fluidos seminais, podendo ocorrer microfissuras no tecido vaginal e retal no ato da penetração sexual e a maior quantidade de vírus nos fluidos sexuais masculinos ${ }^{(17)}$.

A faixa etária mais acometida pelo HIV/AIDS está compreendida entre o intervalo entre 30 - 39 anos. Esses dados são concordantes ao Boletim Epidemiológico disponibilizado pelo Ministério da saúde ${ }^{(18)}$, assim como em outros estu$\operatorname{dos}^{(16,17 ; 19)}$, mostrando que a faixa etária mais acometida está entre jovens adultos.

A Psicologia da Saúde considera os aspectos de religiosidade e espiritualidade como possíveis fontes de apoio social no enfrentamento da doença, especialmente em enfermidades crônicas, como o HIV e aids, a Psicologia Positiva, aponta que as emoções positivas, entre estas a fé e a espiritualidade, auxiliam na manutenção e desenvolvimento saudável mesmo em processo de saúde-doença ${ }^{(20)}$.

É válido analisar, porém, que essas pessoas necessitam de uma assistência contínua e integral, além do compromisso com o seu autocuidado. Isso consiste em um desafio para os pacientes, visto que a convivência com a doença acarreta mudanças em seus cotidianos e pelo fato da aids ainda ser marcada pelo preconceito e estigma social(21).

O enfrentamento desse agravo pode trazer consigo circuntâncias de exclusão e estigma por parte da sociedade, causando ruptura nas relações interpessoais de afeto, sexualidade e socialização. Sabe-se que o estigma, desde o início da epidemia, destacou-se como um dos maiores problemas a serem superados $\mathrm{e}$ que repercute em muitas esferas da vida das pessoas com HIV e aids ${ }^{(22)}$.

Destarte, a qualidade de vida das pessoas vivendo com HIV e aids envolve, além da terapia medicamentosa, os aspectos sociais, religiosos e culturais, os quais são motivos de pesquisa na área da saúde que buscam, a partir das evidências científicas, ofertar atendimento integral, humanizado e resolutivo, compatível com as reais necessidades dessas pessoas desde a prevenção da infecção até a recuperação da saúde ${ }^{(23)}$.

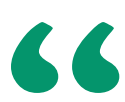

\section{Na atenção à} saúde em geral tem-se buscado não somente métodos de prevenção e controle, mas também estratégias para facilitar e melhorar a vida das pessoas.

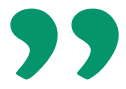

A criança que vive com HIV e aids precisa conviver com a doença, podendo passar por situações difíceis e de confusa compreensão, necessitando de cuidados especiais de seu familiar cuidador, o qual precisa ser devidamente instrumentalizado para o enfrentamento eficaz das situações cotidianas como: o estresse à família que tem no cuidado a esperança de sua cura, e a vírus HIV, quando essa apresenta um machucado com sangramento ${ }^{(24)}$.
Compreendendo o efeito da espiritualidade sobre o viver com HIV através dos relatos dos participantes, as práticas de cuidado poderão ser reorganizadas e reorientadas, levando-se em consideração às subjetividades envolvidas na relação profissional de saúde- pacientefamília, enfatizando como o centro do processo de cuidado, a reabilitação da saúde, prevenção de agravos, tratamento da doença, e a própria pessoa enferma ${ }^{(25)}$. Essa ótica de cuidado beneficia a família dos pacientes, no tocante a inserção de humanização, apoio e participação no atendimento das suas necessidades.

\section{CONCLUSÃO}

A presente investigação se propôs a buscar respostas referentes aos aspectos da qualidade de vida de pessoas vivendo com HIV e aids que sofrem interferência segundo as dimensões psicológica e espiritual. Dessa forma, observa-se que a saúde do ser humano que está acometido por esse agravo tem impacto negativo nas dimensões evidenciadas, sendo importante que os profissionais de saúde atuantes na área possam lançar mão de ações que visem à integralidade do sujeito nas respectivas facetas relacionadas aos aspectos psicológicos e espirituais desses indivíduos.

$\mathrm{Na}$ atenção à saúde em geral tem-se buscado não somente métodos de prevenção e controle, mas também estratégias para facilitar e melhorar a vida das pessoas. A qualidade de vida de pessoas vivendo com HIV e aids não está atrelada apenas a uma oportunidade de vida longa, mas a possibilidade de enfrentar a adversidade de uma doença crônica, de deparar-se com as limitações impostas pela enfermidade, de viver diante de situações de abandono, poucos recursos sociais e econômicos, ruptura nas relações afetivas, problemas com a sexualidade, entre outras situações desagradáveis ao ser humano.

As perturbações psicoemocionais e espirituais decorrentes do diagnóstico 
de uma doença crônica, sem perspectiva de cura, passível de estigma social, bem como as características clínicas da doença e aspectos terapêuticos são fatores que estão diretamente associados à qualidade de vida dessas pessoas.
Os resultados obtidos neste estudo poderão contribuir e fortalecer as linhas de pesquisas relacionadas à atenção às pessoas que vivem com HIV e aids, como também suscitar reflexões entre estudantes e profissionais de saúde e de áreas correlatas, numa dimensão multidisciplinar e interdisciplinar, no sentido de embasar a prática clínica e de implementar estratégias efetivas na assistência prestada na perspectiva de melhorar a qualidade de vida dessas pessoas.

\section{Referências}

1. Brasil. Secretaria de Vigilância em Saúde - Departamento de DST, Aids e Hepatites Virais. Boletim epidemiológico: HIV/AIDS. [Internet]. 2019 [cited 2020 jan. 21]. Brasilia: 2019. Available from: http://www.aids.gov.br/pt-br/ pub/2019/boletim-epidemiologico-de-hivaids-2019

2. Araújo EC, Drosdoski FS, Nunes Júnior NB, Ferreira PGM. Transmissão vertical do HIV em maternidade de referência na Amazônia. Revista Paraense de Medicina [Internet]. 2015 [cited 2020 jan. 11]; 29(2):17-19. Available from: http://www.santacasa.pa.gov.br/data/news/29-2.pdf

3. Bastos RA, BelliniNR, VieiraCM, CamposCJG, Turato ER. Fases psicológicas de gestantes com HIV: estudo qualitativo em hospital. Revista Bioética [Internet]. 2019 [cited 2020 fev. 13]; 27(2):281-8. Doi: 10.1590/198380422019272311

4. Soares ASF, Amorim MISPL. Qualidade de vida e espiritualidade em pessoas idosas institucionalizadas. Revista Portuguesa de Enfermagem de Saúde Mental [Internet]. 2015 [cited 2020 jan. 11]; Esp.(2): 45-50. Available from: http://www.scielo.mec.pt/pdf/rpesm/nspe2/nspe2a08.pdf

5. Whoqol Group. The World Health Organization quality of life assessment (WHOQOL): position paper from the World Health Organization. Social Science \& Medicine [Internet]. 1995 [cited 2020 jan. 11]; 41(10): 1403-9. DOI: https://doi.org/10.1016/0277-9536(95)00112-K

6. Soares AS, Amorim MI. Qualidade de vida e espiritualidade em pessoas idosas institucionalizadas. Revista Portuguesa de Enfermagem de Saúde Mental [Internet]. 2015 [citado 2020 fev. 13]; esp.: 45-50. Availale from http://www.scielo.mec.pt/scielo.php?script=sci arttext\&pi$\mathrm{d}=\mathrm{S} 1647-21602015000100008$

7. Amaral, JF; Ribeiro, JP; Paixão, DX. Qualidade de vida no trabalho dos profissionais de enfermagem em ambiente hospitalar: uma revisão integrativa. Espaç. saúde [Internet]. 2015 [cited 2020 jan. 11]; 16(1):66-74. Available from: http://docplayer.com.br/17821041-Qualidade-de-vida-no-trabalho-dos-profissionais-de-enfermagem-em-ambiente-hospitalar-uma-revisao-integrativa.html

8. Prodanov CC, Freitas EC. Metodologia do trabalho científico: métodos e técnicas da pesquisa e do trabalho acadêmico. 2. ed. Novo Hamburgo: Feevale, 2013. 277p.

9. Baptista MN, Campos DC. Metodologias de pesquisa em ciências: análises quantitativa e qualitativa. 2 ed. Rio de Janeiro: LTC, 2018. 376p.

10. Minayo MCS. 0 desafio do conhecimento: pesquisa qualitativa em saúde. 14. ed. São Paulo: Hucitec, 2012. 416p

11. Ratinaud P. IRAMUTEQ: Interface de R pour les Analyses Multidimensionnelles de Textes et de Questionnaires [Internet]. 2009 [cited 2020 jan. 11]; Available from: http://www.iramuteq.org/

12. Moimaz SAS, Amaral MA, Miotto AMM, Costa ICC, Garbin CAS. Análise qualitativa do aleitamento materno com o uso do software iramuteq. Revista Saúde e Pesquisa [Internet]. 2016 [cited 2020 jan. 11]; 9(3): 567-77. DOI: http://dx.doi.org/10.177651/1983-1870.2016v9n3p567-577

13. Brasil. Ministério da Saúde. Conselho Nacional de Saúde. Resolução ${ }^{\circ}$ 466/12 de 12 de dezembro de 2012. Dispõe sobre diretrizes e normas regulamentadoras de pesquisas envol-vendo seres humanos. [Internet]. 2012 [cited 2020 jan. 09]. Available from: https://portal.fiocruz.br/documento/ resolucao-no-466-de-12-de-dezembro-de-2012

14. Silva Júnior SV, Silva WJC, Lourenço NS, Nogueira JA, Oliveira e Silva
AC, Freire MEM. Quality of life of people living with the human immunodeficiency virus and Acquired immunodeficiency Syndrome. Rev Rene [Internet]. 2019 [cited 2020 fev. 13]; 20(1):e39638. DOI: 10.15253/21756783.20192039638

15. Pereira BPM, Silva NM, Moura LRP, Brito CMS, Câmara JT. Estudo epidemiológico de pacientes com infecção pelo virus da imunodeficiencia humana/ síndrome da imunodeficência adquirida (HIVIAIDS), CAXIAS-MA. Revista Interdisciplinar [Internet]. 2016 [cited 2020 jan. 11]; 9(4): 132-41. Available from: https://dialnet.unirioja.es/ejemplar/507931

16. Duarte LC, Rohden F. As histórias que podem ser contadas: a feminização da epidemia HIVIAIDS e a produção de narrativas científicas. Em construção [Internet]. 2019 [cited 2020 fev. 13]; 5(1):22 - 36. DOI: 10.12957/emconstrucao. 2019.40840

17. Zucchi EM, Grangeiro A, Ferraz D, Pinheiro TF, Alencar T, Ferguson L. Da evidência à ação: desafios do Sistema Único de Saúde para ofertar a profilaxiapré-exposição sexual (PrEP) ao HIV às pessoas em maior vulnerabilidade. Cad. Saúde Pública [Internet]. 2018 [citado 2020 fev. 13]; 34 (7): e00206617. DOI: https://doi.org/10.1590/0102-311X00206617

18. Brasil. Secretaria de Vigilância em Saúde - Departamento de DST, Aids e Hepatites Virais. Boletim epidemiológico: HIV/AIDS. [Internet]. 2016 [cited 2020 jan. 21]. Brasília: 2016. Available from: http://www.aids.gov.br/pt-br/ pub/2016/boletim-epidemiologico-de-aids-2016

19. Silva RAR, Silva RTS, Nascimento EGC, Gonçalves OP, Reis MM, Silva BCO. Perfil clínico-epidemiológico de adultos HIV-positivo atendidos em um hospital de Natal/RN. Cuidado é Fundamental [Internet]. 2016 [cited 2020 jan. 11]; 8(3): 4689-96. DOI: 10.9789/21755361 . 2016.v8i2.4689-4696 20. Silva FS, Oliveira FBM, Mendes CC, Silva G, Santos SO, Pessoa RMC. Preditores associados á qualidade de vida em pessoas vivendo com HIVI aids: revisão integrativa. Rev. Pre. Infec e Saúde [Internet]. 2015 [cited 2020 jan. 11]; 1(2):53-63. Available from: https://revistas.ufpi.br/index.php/nupcis/article/view/3589

21. Araújo LF, Leal BS, Santos JVO, Sampaio AVC. Análise da resiliência entre pessoas que vivem com HIV/AIDS: um estudo psicossocial. Psicologia: Teoria e Pesquisa [Internet]. 2019 [cited 2020 fev. 13]; 35 (1): e35416. DOI: https:// dx.doi.org/10.1590/0102.3772e35416

22. Araújo LF, Lôbo CJC, Santos JVO, Sampaio AVFC. Concepções psicossociais acerca do conhecimento sobre a AIDS das pessoas que vivem com o HIV. Revista Colombiana de Psicología [Internet]. 2017 [cited 2020 fev. 13]; 26(2), 219-30. DOI: http://dx.doi.org/10.15446/rcp.v26n2.59349

23. Oliveira DC, Spindola T, Gomes AMT, Marques SC, Formozo GA, Campos LA. Nurses' symbolic construction of treatment for people living with HIV/ AIDS. Rev enferm UERJ [Internet]. 2015 [cited 2020 fev 13]; 23(5):596-602. DOI: http://dx.doi.org/10.12957/reuerj.2015.13191

24. Ferreira SL, Sousa IV, Fernandes MVC, Esteves AVF, Rocha EP. A percepção de cuidadoras sobre os cuidados com a criança soropositiva ao HIV. Enfermagem Brasil [Internet]. 2019 [cited 2020 fev 13]; 18(3):365-72. DOI: http:// dx.doi.org/10.33233/eb.v18i3.2243

25. Pinho CM, Dâmaso BFR, Gomes ET, Trajano MFC, Andrade MS, Valença MP. Religious and spiritual coping in people living with HIV/Aids. Rev Bras Enferm [Internet]. 2017 [cited 2020 fev 13]; 70(2):392-9. DOI: http://dx.doi. org/10.1590/0034-7167-2015-0170 